\title{
Für den Samariter B.T.
}

Es traf die Nachricht am Rapport.

Einer schwieg bei uns und ging fort.

Brach das Genick unter Leistungsdruck

Vor Gesichtsverlust und Erwartungsdruck.

Alle trauerten, einer bestürzt, der andere bedächtig

Dem Mörderischen nachzufragen war keiner mächtig

Eine Epidemie tobte, namens shareholder value Angst und Unsicherheit säte mit blutarmer Salü Vielleicht bündelten sich zum Strick unsere Augenschwellen Zum Strang wurden gestrickt die Stimmenwellen

Das Blut der Rebe tranken wir dann krugvoll Es schien uns alles glanzvoll leer und hohl Der Jugend im Discorausch dünkte alles so cool Die zwischenmenschliche Beziehung bewegte sich um null Man sprach laut und lustig unterm Alkohol Mancher fühlte sich mutig, berauscht und wohl Nüchtern fanden wir uns wieder einsam Uns verbanden lediglich Sehnsüchte gemeinsam: Geliebt, geachtet, erfüllt in Seele und Leib Geschätzt, geborgen im Beruf und beim Weib

Er ertrank in der Fata Morgana des Scheins, Jeder rannte auf sich gestellt, Wir fühlten uns nicht Eins Kein Vertrauen wuchs unter uns, Dass er einen Laut gab, Ihm schwankte der Boden bedrohlich unterm Fuß Der Samariter brach zusammen bei der Mitmenschenpflege Keine Stütze fand die Flanke gar im Schützengehege.

Kazem Mohtadi, Zofingen 